\title{
Duodenal Varices: A Rare Manifestation of Portal Hypertension
}

\author{
Deepankar Kumar B ${ }^{1 *}$, Ronald Gomes $\mathbf{R}^{2}$ and Samsul Arfin ${ }^{3}$ \\ ${ }^{1}$ Associate Consultant-Medicine, Square Hospitals Ltd, Bangladesh \\ ${ }^{2}$ Clinical Staff-Gastroenterology, Square Hospitals Ltd, Bangladesh \\ ${ }^{3}$ Consultant-Gastroenterology, Square Hospitals Ltd, Bangladesh
}

Submission: November 26, 2017; Published: December 11, 2017

*Corresponding author: Deepankar Kumar Basak, MBBS, FCPS, Associate Consultant-Medicine, Square Hospitals Ltd, Bangladesh,

Tel: 01760499475; Email: deepankarbasak@gmail.com

\section{Summary}

We report a case of haematemesis \& melaena due to ectopic varices located in the duodenum in a patient with Nash related CLD. Duodenal varices are a rare but potentially serious consequence of portal hypertension in the event of a bleeding. The etiology of duodenal varices can be classified into hepatic (e.g. cirrhosis) or extra hepatic (e.g. portal, splenic or superior mesenteric vein thrombosis). Endoscopic injection sclerotherapy (EIS) and endoscopic variceal ligation (EVL) are widely accepted as primary therapies for esophageal variceal bleeding whereas bleeding gastric fundal varices are usually treated with cyanoacrylate injection or shunt procedures. However there is no widely accepted treatment modality for duodenal varices. In the case presented, we used injection sclerotherapy with ethanolamine oleate, to obliterate varices and control bleeding. A short review on the etiology pathogenesis and management of ectopic varices is presented.

Keywords: Ectopic varices; Cirrhosis; Gastrointestinal bleeding; Portal hypertension; Injection sclerotherapy

\section{Introduction}

Duodenal varices are a rare but potentially serious consequence of portal hypertension in the event of a bleeding. The etiology of duodenal varices can be classified into hepatic (e.g. cirrhosis) or extra hepatic (e.g. portal, splenic or superior mesenteric vein thrombosis). Endoscopic injection sclerotherapy (EIS) and

endoscopic variceal ligation (EVL) are widely accepted as primary therapies for esophageal variceal bleeding whereas bleeding gastric fundal varices are usually treated with cyanoacrylate injection or shunt procedures. However there is no widely accepted treatment modality for duodenal varices.
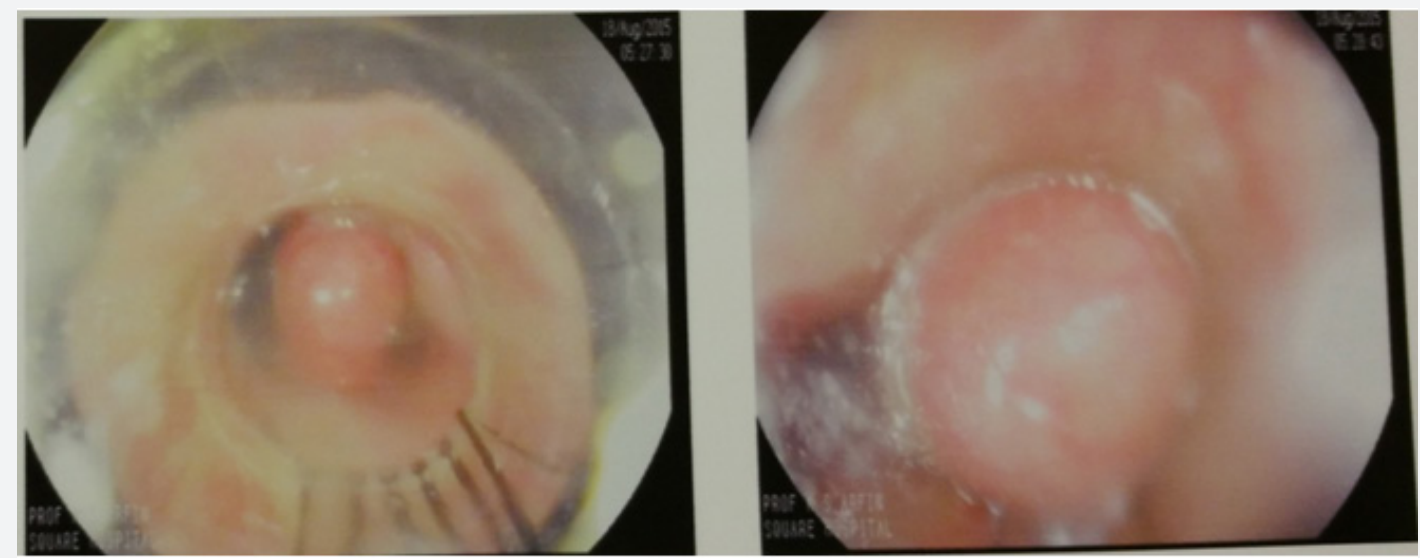

Figure 1: EVL of esophageal varices. 


\section{Case Report}

Mrs. Meherunnessa, age 46 yrs known case of NASH related CLD with extra hepatic portal vein obstruction, diabetes mellitus and Sheehan syndrome admit in SHL through ER with the complaints of altered level of consciousness, jaundice, haematemesis and melaena for 3 days. She was a history of ERCP with stenting in CBD for proximal CBD stone 6 months back with cholecystectomy 2003. At first she admits in the ICU of Rangpur medical college and got 6 units whole blood. Though condition is not improved and bleeding was continued, patient was referred to SHL ICU for better management. During admission in ICU, patient was drowsy GCS E3M4V4, severely anemic $\mathrm{Hb} 7.5 \mathrm{gm} / \mathrm{dl}$, platelet $57 \mathrm{~K} / \mathrm{ul}$, icteric bilirubin $4.8 \mathrm{mg} / \mathrm{dl}$, ALT 131U/l, AST 130U/l, ALP 307U/l, albumin 1.9gm/dl. She got 2unit of PRBC and 1 unit aphaeresis platelet with inj. stilamin in infusion pump. Bleeding was stopped \& her consciousness level improved. She underwent endoscopy found grade3 esophageal varices (Figure 1), congested gastropathy and bleeding duodenal varices (Figure 2). 1st session of sclerotherapy of duodenal varices with EVL of esophageal varices was done.

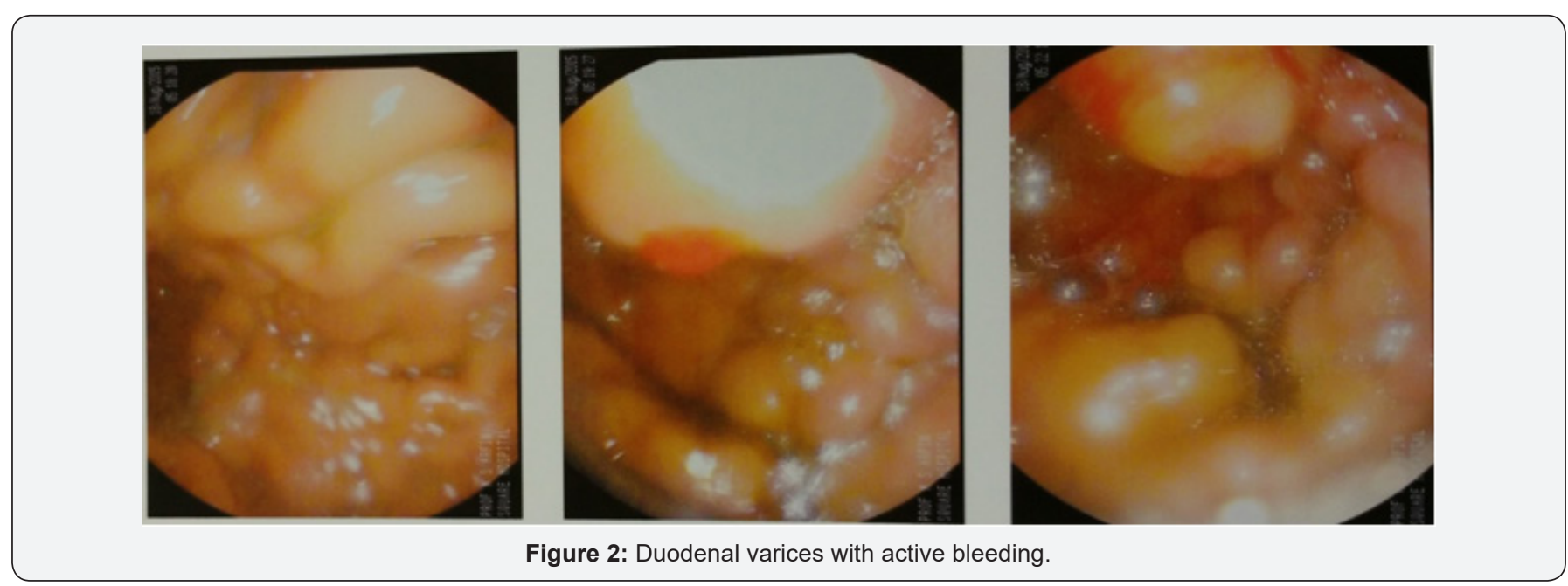

Patient was then shifted to cabin. Inj.stilamin was stopped after 72 hours. She was observed for another 3 days for any haematemesis \& melaena. Now she was stable and discharged with advice of 2 nd session EVL and sclerotherapy.

\section{Discussion}

Ectopic varices are natural large port systemic venous collaterals which appear apart from the gastro esophageal region anywhere in the abdomen [1]. They are usually found in patients with portal hypertension although familial occurrence in the absence of portal hypertension has been reported [2,3]. The prevalence of ectopic varices depends on the technique used for diagnosis and on the etiology of portal hypertension. It is reported to appear in $1 \%$ to $5 \%$ of cirrhotic patients and up to $20 \%$ to $30 \%$ of patients with extra hepatic portal hypertension. The location of the varices also depends on the cause of portal hypertension [2]. Duodenal varices are found by angiography in more than $40 \%$ of patients with extra hepatic portal hypertension (due to obstruction of the portal or splenic vein). Varices in other sites of the small or large intestine are commonly found in patients with cirrhosis, especially in those with history of abdominal surgery, stomas etc. (e.g. patients with primary sclerosing cholangitis who have undergone colectomy and ileostomy for underlying inflammatory bowel disease). Although commonly present duodenal varices rarely bleed. The first report of bleeding from duodenal varices was presented by Alberti et al. [4]. Bleeding can be fatal and mortality rates may reach $35 \%$ to $40 \%$ [5-7].
The duodenal bulb is the most common location of duodenal varices. Their frequency decreases at the distal duodenum [8]. They are usually located in the deeper layers of the duodenal wall, in contrast to the submucosal position of the esophageal varices. If they are not endoscopically seen, they have no clinical value, since they never bleed. The afferent vessel of the varix is usually the superior or inferior pancreaticoduodenal vein, the superior or inferior mesenteric vein and sometimes the gastroduodenal or pyloric veins [9]. The efferent vein drains into the inferior vena cava either directly or through the retroperitoneal veins. Duodenal varices seem to have smaller diameter and shorter length than esophageal varices. Wall tension (depending on the vessel size and the portal pressure) seems to be the major determinant of risk of rupture [10]. The formation of duodenal varices depends on the etiology of portal hypertension. In patients with extra hepatic portal hypertension varices spring from portal-to-portal anastomoses connecting afferent branches of the portal vein, upstream of the obstruction. In patients with previous abdominal surgery, adhesions can be formed between the bowel and the abdominal wall or between other abdominal structures drained by the systemic venous circulation. Collaterals, within the wall of the duodenum may open up. Finally, there have been reports of formation of duodenal varices after injection slcerotherapy or ligation of esophageal or gastric varices [11]. This is probably due to post-treatment alterations in the hemodynamic of portal flow.

Management of bleeding duodenal varices is difficult and depends on local expertise and the cause of portal hypertension. The 
optimal therapy has been debated in the literature. There are reports of treatment with injection sclerotherapy with different types of sclerosant agents such as ethanolamine, polidocanol, dextrose $50 \%$ solution with $3 \%$ sodium tetradecylsulfate, polidocanol/thrombin $[12,13]$. Emergency sclerotherapy has been shown to be useful as a first-line therapeutic measure in the treatment of bleeding duodenal varices. Endoscopic variceal ligation of ectopic varices has been reported [14], but some authors believe that the banding technique is unsafe for large ectopic varices, since the entire varix cannot be banded and there is also a risk of causing a wide defect in the varix after sloughing off the band [1]. Embolization therapy using radiological techniques is an alternative in the short term management of bleeding ectopic varices and controls bleeding in up to $94 \%$ of cases $[15,16]$. However rebleeding rates over 1 year are high. If the patient continues to bleed, options include either using a TIPS or proceeding with surgery. Surgery is preferred in patients with Child-Pugh class A and in patients with extra hepatic portal vein thrombosis. In the review of Khouqeer et al. [6] on the surgical treatment of duodenal varices, the portocaval shunt was the most effective method of preventing recurrent hemorrhage. TIPS are effective in controlling bleeding in the acutephase but up to $50 \%$ of TIPS will stenose in 6 months and long-term mortality is high, due mainly to poor liver function $[17,18]$. Thus TIPS can be used in patients with Child- Pugh class B or C, who are candidates for liver transplantation, if endoscopic or radiological embolization therapy fail.

\section{References}

1. Norton I, Andrews JC, Kamath PS (1998) Management of ectopic varices. Hepatology 28(4): 1154-1158.

2. Lebrec D, Benhamou JP (1985) Ectopic varices in portal hypertension. Clin Castroenterol 14(1): 105-121.

3. Stephan G, Miething R (1968) Rongendiagnostik varicoser Duodenalveranderungen bei portaler Hypertension. Der Radiologe 3: 90-95.

4. Alberti W (1931) Uber den rotgenologischen nachweis von varizen im bulbus duodeni. Fortschr Geb Rontgenstr 43: 60-65.

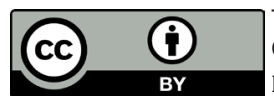

This work is licensed under Creative Commons Attribution 4.0 License DOI: 10.19080/ARGH.2017.08.555736
5. Cappell MS, Price JB (1987) Characterization of the syndrome of small and large intestinal variceal bleeding. Dig Dis Sci 32(4): 422-427.

6. Khouqeer F, Morrow C, Jordan P (1987) Duodenal varices as a cause of massive upper gastrointestinal bleeding. Surgery 102(3): 548-552.

7. Amin R, Alexis R, Korjis J (1985) Fatal ruptured duodenal varix: A case report and review of the literature. Am J Gastroenterol 80: 13-18.

8. Tanaka T, Kato K, Taniguchi T, Takagi D, Takeyama N, et al. (1998) A case of ruptured duodenal varices and review of the literature. Jpn Surg 18(5): 595-600.

9. Hashizume M, Tanoue K, Ohta M (1993) Vascular anatomy of duodenal varices: angiographic and histopathological assessments. Am J Gastroenterol 88(11): 1942-1945.

10. Groszmann RJ (1984) Reassessing portal venous pressure measurements. Gastroenterology 86(6): 1611-1614.

11. Eleftheriadis E (1988) Duodenal varices after sclerotherapy fo esophageal varices. Am J Gastroenterol 83: 439-441.

12. Tsuzi H, Okano H, Fuzino H (1989) A case of endoscopic injection sclerotherapy for a bleeding duodenal varix. Gastroenterol Jpn 24(1): 60-64.

13. Sans M, Llach J, Bordas JM, Andreue V, Reverter JC, et al. (1996) Thrombin and ethanolamine injection therapy in arresting uncontrolled bleeding from duodenal varices. Endoscopy 28(4): 403.

14. Shirashi M, Hiroyasu S, Higa T, Oshiro S, Muto Y (1999) Successful management of ruptured duodenal varices by means of endoscopic variceal ligation: report of a case. Gastrointest Endosc 49(2): 255-257.

15. Haruta I, Isobe Y, Ueno E (1996) Balloon-occluded retrograde transvenous obliteration (BRTO), a promising nonsurgical therapy for ectopic varices: a case report of successful treatment of duodenal varices by BRTO. Am J Gastroenterol 91: 2594-2597.

16. Menu T, Gayet B, Nahum H (1987) Bleeding duodenal varices: diagnosis and treatment by percutaneous portography and transcatheter embolization. Gastrointest Radiol 12(1): 111-113.

17. Haskal Z, Scott M, Rubin RA (1994) Intestinal varices: treatment with the transjugular intrahepatic portosystemic shunt. Radiology 191(1): 183-187.

18. Jonnalagadda SS, Quiason S, Smith OJ (1998) Successful therapy of bleeding duodenal varices by TIPS after failure of sclerotherapy. Am J Gastroenterol 93: 272-274.

\section{Your next submission with Juniper Publishers will reach you the below assets}

- Quality Editorial service

- Swift Peer Review

- Reprints availability

- E-prints Service

- Manuscript Podcast for convenient understanding

- Global attainment for your research

- Manuscript accessibility in different formats

( Pdf, E-pub, Full Text, Audio)

- Unceasing customer service

Track the below URL for one-step submission

https://juniperpublishers.com/online-submission.php 